\title{
Aportaciones a la obra artística de José Guisado en la provincia de Sevilla
}

\author{
M. ${ }^{a}$ Teresa Ruiz Barrera \\ Universidad de Sevilla \\ mariateresaruizbarrera@gmail.com
}

El objetivo del presente artículo es ofrecer nuevos datos sobre la obra de José Guisado, uno de los maestros de la retablística activos en Sevilla entre los siglos XVII y XVIII. Con este fin aportamos una documentación inédita consultada en la sección de Protocolos Notariales del Archivo Histórico Provincial hispalense que desvelan parte de su quehacer artístico en el periodo comprendido entre 1692 y 1701, tanto en la capital como en diversas localidades de la provincia.

José Guisado, de probable origen sevillano, vivió en las collaciones de san Martín y de Omnium Sanctorum, a las que hay que añadir ahora la de san Vicente en la que vivía en 1692. Por la época en que trabajó empleó en sus máquinas lignarias los soportes salomónicos, tal y como confirmamos en uno de los contratos.

La escasa nómina de las obras adjudicadas a este artista contempla seis de finales del siglo XVII y dos de inicios del siglo siguiente. En 2 de julio de 1692 Guisado y el pintor Marcos de Velasco conciertan un retablo para la capilla de la hermandad de la Santísima Cruz y san Francisco de Sena, en la iglesia de san Bartolomé de Sevilla, y en el mismo año, firma también la ejecución de un retablo para la capilla de la hermandad hispalense de Nuestra Señora de la Estrella (Sanz, 1973: 342-347, 45-46).

En 1694 firman escritura de un nuevo retablo para La Puebla del Río José Guisado como maestro ensamblador y su amigo Luis González como maestro tallador (Navarro, 2012). Hacia 1697 hace el retablo mayor de la Colegiata de Olivares (Sevilla), obra conjunta con Matías de Brunenque y José Escobar. Y en el mismo año Guisado contrata una sillería coral para la parroquia de Mairena del Alcor (SeviIla) (Halcón, 2009: 72). Dos años después, concretamente el 13 de julio, se compromete a realizar el retablo mayor de la iglesia parroquial de santa María Magdalena de El Arahal (Sevilla), obra por desgracia desaparecida (De la Villa, 1993:
91). Asimismo son conocidos su irrealizado proyecto para el retablo mayor de la colegiata de Osuna en 1704 (Gutiérrez, 1987: 211-218; Rodríguez-Buzón, 1980: 9-39) y, como escultor, el contrato para adornar el paso de san Juan Bautista de la iglesia de san Francisco de Paula de Sevilla concertado en 6 de abril de 1704 (Sancho, 1934: 45-46). A estas obras añadimos en estas páginas cuatro: un retablo mayor para una parroquia, dos retablos laterales, una custodia procesional y la ornamentación de un paso procesional para distintas cofradías. Se expondrán por orden cronológico.

En 27 de agosto de 1692 José Guisado y Luis González, ambos maestros arquitectos, firman contrato para realizar el antiguo retablo mayor de la parroquia de santa María Magdalena de Villamanrique (hoy Villamanrique de la Condesa) morando en esa población los seis meses en los que se ajustó la obra. Pino de Flandes para el retablo en sí y cedro para sus adornos y talla de la santa titular fueron las maderas elegidas. En el contrato se especifican ciertas modificaciones al diseño original que concernieron al sagrario; al camarín que se amplió en ornato y espacio al igual que el propio nicho de la santa titular de la parroquia; a las cornisas y pilastras principales que, junto con «el banquillo del ultimo cuerpo que esta muy Pobre», debían adornarse más y también las entrecalles en forma y decoración así como «enriquecer mas de obra el Ultimo Cuerpo y los arbotantes». Ambos artistas comprarían la madera necesaria con un adelanto del dinero y subrogarían con un pintor el realizar los lienzos para las entrecalles, los cuales «an de ser de pintura de Buena mano», o presentárselo directamente a la comisión de Villamanrique para que esta lo contratase. El hecho de que no mencionen buscar a un escultor para la talla titular induce a pensar que bien Guisado bien Luis González se encargaría de realizarla. El precio ajustado -trescientos ducados de vellón- se pagaría en los habituales tres plazos: primero cien ducados de los 
cuales quinientos reales se destinaron a comprar la madera -dinero recibido de manos de Diego Román de Andrina, vecino de la villa de Villamanrique-; otros tantos mediada la obra y los últimos una vez terminado y colocado el retablo. En el montante general se incluía la cantidad destinada al maestro pintor junto con el coste del material y traslado de los lienzos a la villa así como del montaje del retablo en la capilla mayor. Como era habitual, los artistas se comprometían a asumir el incremento del precio del retablo si no lo acababan y debían hacerlo otros maestros ${ }^{1}$. Estructuralmente el retablo constaría de un banco, que incluiría el sagrario, un único cuerpo y ático. El camarín central acogería a santa María Magdalena y en las entrecalles dispuestas en dos alturas lucirían cuatro lienzos, de desconocida temática, a más de otro del Señor Santiago a disponer en el ático. La desaparecida máquina lignaria debió presidir la antigua iglesia mudéjar de la villa (Vázquez, 1961: 38).

Se conserva una imagen de la santa titular de la parroquia, María Magdalena [1], que identificamos con la que se contrató junto con el retablo. De bulto redondo tallado en madera policromada, pues debía procesionar, mide aproximadamente lo que especifica la escritura contractual, «asta altura de siete cuartas ynclusa en ella la peana»². Iconográficamente es una Magdalena penitente (Delenda, 2001: 283-286). Desconocemos con certeza su autoría pues podría ser tanto Guisado como González. El segundo es denominado maestro tallista o escultor en la escritura de La Puebla y Guisado se nombra escultor en un contrato que estudiaremos en breve. Otra opción es un maestro escultor contratado para ello. Sea quien sea se nos muestra como un artista de modelado correcto en sus formas. Vestida con el simulacro de una tosca túnica de estera de palma ceñida por un lazo y mostrando sus brazos desnudos y pies descalzos, el cuerpo se adelanta levemente descansando sobre la pierna derecha, en ligero contraposto con el rostro que se gira suavemente hacia la izquierda. Se singulariza por larga y ondulada cabellera oscura que partida en dos se desliza por sus hombros hasta casi las caderas y hace referencia tanto a su antigua vida como a que con ella enjugó los pies de Jesús. El rostro presenta facciones ovaladas, pómulos poco sobresalientes, nariz recta y cejas finas así como los labios entreabiertos. Posee una mirada anhelante dirigida hacia el crucifijo que aferra su mano izquierda al cual dedica su vida contemplativa y penitente, al tiempo que la derecha reposa sobre su pecho, en alusión a la aceptación de esa nueva vida y recalcando su expresión mística. Creemos que sigue la impronta dejada en la que creara Pedro de Mena en 1664, uno de los prototipos barrocos de la Magdalena arrepentida.

Cinco años después, en 8 de enero de 1697, Guisado como maestro escultor se obliga con Luis de Ballesteros, mayordomo de la hermandad sacramental de la iglesia de san Sebastián de Alcalá de Guadaira, a entregar a su perfección «asi de escultura como de dorado y estofado la custodia que tiene la hermandad" para antes del Jueves Santo del mismo año, por lo que el tiempo de ejecución de la obra estaría en torno a los tres o cuatro meses. El coste total ascendió a setecientos cincuenta reales de vellón. En este caso se acordaron sólo dos plazos recibiendo en el primero ciento noventa y un reales. Nuevamente nos encontramos con otra obra en colaboración pues el tallado de la Custodia sería obra suya pero contrató ese mismo día a Pedro de Escobar para el dorado y estofado adjudicándole seiscientos reales $^{3}$. Así pues Guisado realmente cobró por su trabajo ciento cincuenta reales.

El artista finalizó el año de 1697 con un importante contrato de dos retablos. A 10 de diciembre firma en colaboración con el maestro dorador y estofador Lorenzo Vallejo, dichos retablos para la iglesia conventual de san Basilio de Sevilla. Ambos afirman «que tomamos por nuestra quenta el dorar y estofar a toda costa y a satisfasion de gonzalo montes de oca, maestro del arte de la seda, vecino desta ziudad dos retablos» ${ }^{4}$. Estos se destinaron a la capilla de la hermandad del Santo Cristo de la Humildad, sita entonces en el Colegio de san Basilio ${ }^{5}$. Un retablo estaba dedicado a la propia imagen cristífera «y el otro el de nuestra señora», cuya advocación no se especifica pero suponemos debía ser Nuestra Señora del Subterráneo. Debían dorarlos "y frisándolos de color concha de carey» para entregarlos mediada la cuaresma del siguiente año, es decir, tras unos tres o cuatro meses. La tasación alcanzó los cuatrocientos cincuenta ducados de vellón a pagar cada sábado a razón de «diez pesos escudos de los de a diez reales de plata» y concluida la obra, se pagaría la cantidad restante.

Finalizando casi el siglo, en 1698, realiza como maestro arquitecto un «sitial del paso y la coronación», para otra cofradía, la de la Presentación de Nuestro Señor Cristo del hispalense templo de san Ildefonso. Su principal fiador era Francisco Pasilla, también maestro en el arte de la seda. Gui- 
sado se obliga con los oficiales y hermanos de la cofradía a hacer «de escultura el sitial del paso y la Coronacion del, de madera nueba de cedro según dibujo que tengo firmado yo el principal y el presente escribano que a de ir con quatro derames la tumbilla del cielo Rompido de talla sobre sano como esta en el dicho dibujo y no a de ir con el Jesus que tiene porque en lugar del a de llevar / Mitra y baculo de señor san Ydelfonso y la insignia de la cofradía. Y alrededor del paso a de llevar la coronasion como esta en dicho dibujo a las espaldas del grande y también a de llevar los atributos de la pasión y los remates an de ser de sipres y tambien hemos de hacer dos baras de madera salomónica». Toda la obra debía acabarse y colocarse en la misma capilla en los seis meses siguientes a contar desde el mes de la fecha del contrato, 9 de junio de 1699 tal y como firman el artista y los representantes de la hermandad, a la sazón el prioste Pedro de Cuadros, los dos alcaldes Antonio de Medina y Tomás Marcelo, los mayordomos Antonio Duarte y Antonio de Sayas, el fiscal Francisco de Rojas y Pedro José Escribano. Se tasó la obra en quinientos reales. De ellos recibiría cien reales al principio y el resto "como lo pudieren pagar y se fuere obrando». Para la ejecución de las piezas y descuento del precio, como era en muchos casos habitual la hermandad acordó con el maestro entregarle parte del material que abarataría la obra: el viejo sitial y tres tablas nuevas de cedro ${ }^{6}$.

La última noticia que aportamos sobre José Guisado es un contrato de aprendizaje como maestro ensamblador de retablos firmado a 14 de diciembre de 1701 con Isabel de Pedrasa, vecina de la collación de san Martín. Esposa de José Martínez del Rincón, el cual estaba «ausente en Yndias», es la que pone a su hijo Leonardo Martínez del Rincón, de catorce años, a aprender el oficio con Guisado por tres años ${ }^{7}$.

Como conclusiones cabe recordar que se constatan documentalmente cuatro nuevas obras de Guisado que aportar a su escasa nómina conocida. Con la primera pieza artística fechada en 1692 ampliamos, además, la actividad de Guisado en cinco años antes de las noticias publicadas con anterioridad. Así pues, por ahora y a la espera de nuevas noticias sobre su actividad, ésta queda comprendida entre 1692 y 1704. Igualmente, el hecho de saberle vecino de la collación de san Vicente amplía también su «movili-

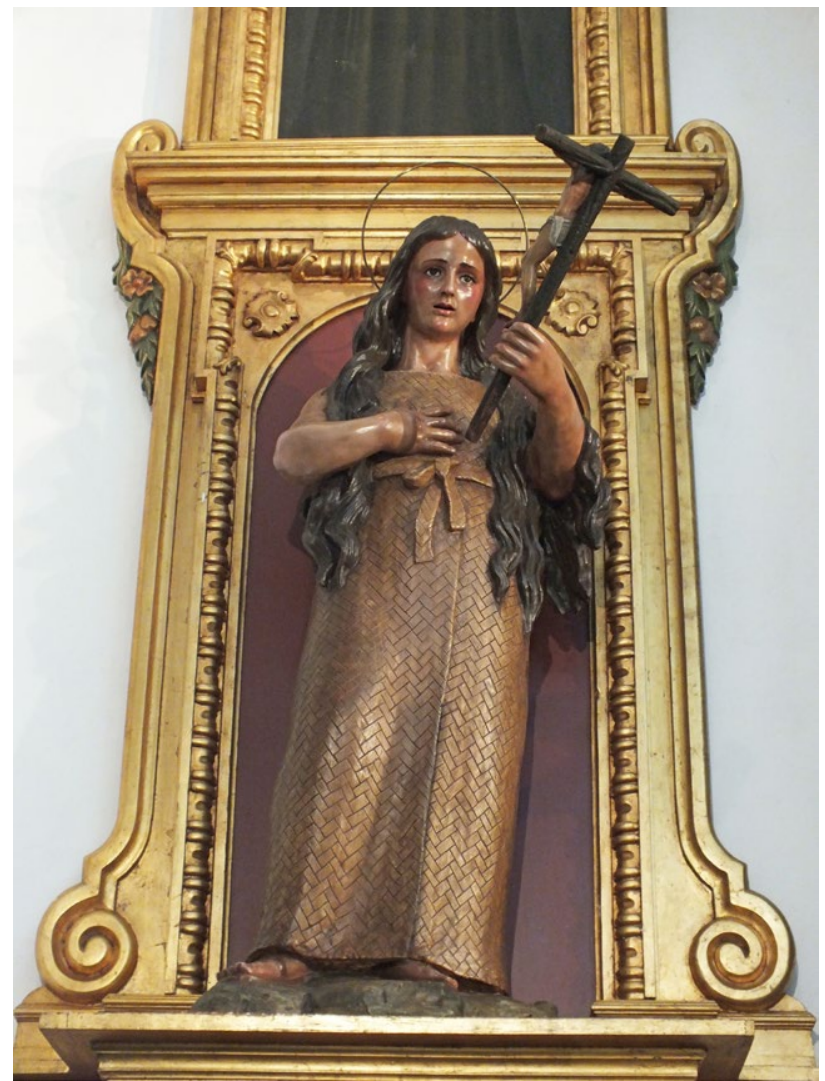

1. Magdalena Penitente. Parroquia de Santa María Magdalena. Villamanrique de la Condesa

dad» dentro de la capital. Es de interés recalcar que en sólo una -la que debía realizar para la cofradía de la Presentación de Jesucristo en san Ildefonso-, es el único artista encargado de ella, mientras que en las restantes bien firma con Luis González o Lorenzo Vallejo o bien subroga el contrato como es el caso con Pedro de Escobar. En estos casos obedece a la práctica un tanto generalizada de firmar el contrato de toda la obra desde el tallado hasta el dorado y/o estofado que se requiriesen como principal maestro y por tanto, responsable, aunque más tarde se contratara a los maestros de las artes específicas para llevar a buen término la pieza artística completa. Por último, debe constatarse que su actividad englobó tanto ser maestro ensamblador o arquitecto de retablos como escultor. 


\section{Notas}

1 Archivo Histórico Provincial, Sevilla (AHP Sevilla). Sección Protocolos Notariales. Oficio 4. Escribano público Juan Muñoz Naranjo. Legajo 2.779. Año 1692. ff. 794r-795v. El contrato es firmado por Juan de Aguilar, el escribano y Guisado no así por Luis González dado que no sabía hacerlo como se asegura en la escritura del retablo de La Puebla del Río. Signan también en calidad de fiadores Francisco de Espinosa y el maestro dorador Juan de Molina Navarro, vecino de la collación de san Vicente a igual que Guisado y González. A propósito del maestro dorador se conocen las buenas relaciones que le unían, al menos, con Luis González, pues éste fue su fiador cuando en 1694 contrata la labor de dorado del paso de la cruz de la hispalense Cofradía del Santo Entierro, sita en el colegio mercedario de san Laureano, Sancho, 1982: 648.

2 AHP Sevilla. Sección Protocolos Notariales. Oficio 4. Escribano público Juan Muñoz Naranjo. Legajo 2.779. Año 1692. f. 794r.

3 AHP Sevilla. Sección Protocolos Notariales de Sevilla. Oficio 1. Escribano Bernardo García. Legajo 661. Año 1697. Primer libro, ff. 12r-13v. Guisado dice ser vecino de la collación de Omnium Sanctorum.

4 AHP Sevilla. Sección Protocolos Notariales de Sevilla. Oficio 1. Escribano Bernardo García. Legajo 662 Año1697. Segundo libro, ff. 511r-512v. Guisado se dice avecindado en Omnium Sanctorum mientras que Vallejo es de la collación de san Isidoro. Por su parte, de Gonzalo Montes de Oca que asumió el coste del dorado y estofado de los retablos, conocemos que era ya maestro en su oficio en 11 de febrero de 1695, fecha en que suscribe un contrato de aprendizaje, AHP Sevilla. Sección Protocolos Notariales de Sevilla. Oficio 1. Escribano Bernardo García. Legajo 657. Año 1695. Primer libro, ff. 214r -214v. Recibe como aprendiz a Juan de Valderrama, de trece años, que es puesto por su padre, Andrés de Valderrama, durante un trienio. Montes de Oca vivía entonces en la collación de san Lorenzo.

5 Esta hermandad, anteriormente llamada del Santo Cristo Humillado nació a mediados del siglo XV y radicaba en el Hospital de san Lázaro. En 1613 se hallaba en el Colegio Basilio junto con la de la Virgen del Subterráneo. Posteriormente se fusionó con la hermandad de la Santa Cena, Pérez, 2003: 194, 197, 209.

6 AHP Sevilla. Sección Protocolos Notariales de Sevilla. Oficio 1. Escribano Bernardo García. Legajo 665. Año 1699. Primer libro, ff. 804r-805v. Continua viviendo en Omnium Sanctorum. El costo total ascendió a 2.600 reales. Respecto a la antigua Hermandad de la Presentación de san Ildefonso, puede consultarse Roda, 1997: 56-57.

7 AHP Sevilla. Sección de Protocolos Notariales de Sevilla. Oficio 1. Escribano Bernardo García. Legajo 670. Año 1701. Libro 2., ff. 1289r-1289v.

\section{Bibliografía}

DE LA VILLA NOGALES, Fernando y MIRA CABALLOS, Esteban (1993), Documentos inéditos para la Historia del Arte en la provincia de Sevilla. Siglos XVI al XVIII, Sevilla Gandolfo, Sevilla.

DELENDA, Odile (2001), "La Magdalena en el arte. Un argumento de la contrarreforma en la pintura española y mejicana del siglo XVIl», en Actas III Congreso Internacional del Barroco americano: Territorio, Arte, Espacio y Sociedad, Universidad Pablo de Olavide, Sevilla, pp. 277-289.

GUTIÉRREZ MOYA, César (1987), «Nuevas noticias sobre el Retablo Mayor de la Colegiata de Osuna», Archivo Hispalense: revista histórica, literaria y artística, vol. 70, n. ${ }^{\circ} 214$, pp. 211-218.

HALCÓN, Fátima, HERRERA, Francisco J. y RECIO, Álvaro (2002), El retablo barroco sevillano, Universidad de Sevilla, Sevilla.

- (2009), El retablo sevillano. Desde sus orígenes a la actualidad, Fundación Cajasol, Sevilla.

NAVARRO GRAU, Juan (2012), «El largo camino del retablo mayor de Ntra. Sra. de la Granada de La Puebla junto a Coria». En: <www. Cuadernos de Casa Alta> (fecha de consulta: 2-enero-2016).

PÉREZ GONZÁLEZ, Silvia María (2003), «Antigua, Real, llustre y Fervorosa Hermandad Sacramental y Cofradía de Nazarenos de la Sagrada Cena, Santísimo Cristo de la Humildad y Paciencia, Nuestra Señora del Subterráneo", en SÁNCHEZ HERRERO, José; RODA PEÑA, José; GARCÍA DE LA CONCHA DELGADO, Federico (coords.), Misterios de Sevilla, I, Ediciones Tartessos, Sevilla, pp. $193-227$.

RODA PEÑA, José (1997), «Documentos inéditos sobre pasos procesionales sevillanos del siglo XVIl», Boletín de las Cofradías de Sevilla, n. ${ }^{\circ} 461$, pp. $56-57$.

RODRíGUEZ-BUZÓN CALLE, Manuel (1979), «Riesgos y venturas del Retablo Mayor de la Colegiata de Osuna», Archivo Hispalense, vol. 190, pp. 9-39.

SANCHO CORBACHO, Heliodoro (1934), «Arquitectura sevillana del siglo XVIII», en Documentos para la Historia del Arte en Andalucía, t. VII, Universidad de Sevilla, Laboratorio de Arte, Sevilla, pp. 45-46.

- (1982), «Artífices sevillanos del siglo XVIl», en Homenaje al Profesor Doctor don José Hernández Díaz, t. I, Universidad de Sevilla, Facultad de Geografía e Historia.

SANZ SERRANO, M. ${ }^{a}$ Jesús y DABRIO, M. ${ }^{a}$ Teresa (1973), «Documentos de artistas sevillanos del siglo XVIII», Archivo Hispalense, n. ${ }^{\circ}$ 171173, pp. 341-370.

VÁZQUEZ SOTO, José (1961), Historia y leyenda de Villamanrique, Editorial Católica, Sevilla. 